\title{
Opinion
}

\section{Practicing humility and medical education: Lessons learnt interviewing experts on Paediatric Virology}

\author{
IOANNIS N. MAMMAS ${ }^{1-3}$ and DEMETRIOS A. SPANDIDOS ${ }^{1}$ \\ ${ }^{1}$ Laboratory of Clinical Virology, School of Medicine, University of Crete, 71003 Heraklion; ${ }^{2}$ First Department of Paediatrics, \\ University of Athens School of Medicine, 11527 Athens; ${ }^{3}$ Paediatric Clinic, Aliveri, 34500 Island of Euboea, Greece
}

Received July 22, 2019; Accepted August 26, 2019

DOI: $10.3892 /$ etm.2019.7953

'I live to serve life'

George N. Papanicolaou

The first manuscripts by Dr George N. Papanicolaou (1) were not medical, but philosophical. While conducting his postgraduate studies in Freiburg in Germany, the 25-year old junior doctor from the island of Euboea wrote for the Greek literature journal, O Noumas. His article, written in Greek, was entitled 'About egoism and egoists' and was published in three parts, focusing on private, social and national egoism. $\mathrm{He}$ writes in the first part published on November 23rd, 1908 (2): 'The concept of the ego is nothing, but a metaphysical construct. Our entire life is a series of reactions to the actions of the environment. And our soul is constantly changing, along with our spirit and character, our ideas and feelings, from the moment our existence will assume its apparent individuality to the moment that it will be re-sank in the cosmic universe. This is how we understand Nature and Life, we, the children of Spinoza and Goethe, and for this reason we disdain egoism and consider egoists as ignorant and barbaric.' ['H évvoı $\alpha$

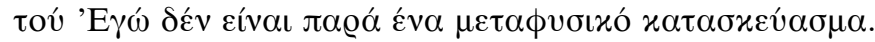

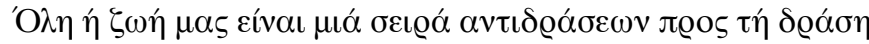

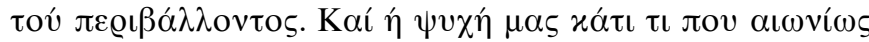

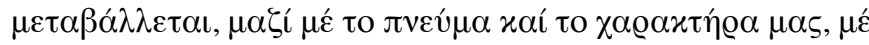

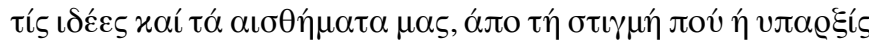

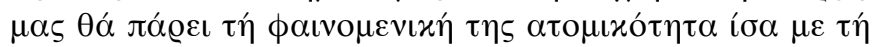

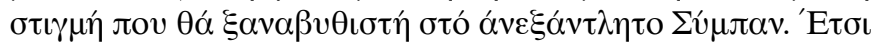

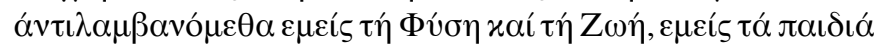

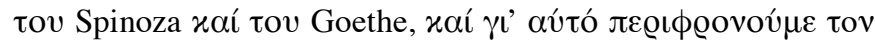

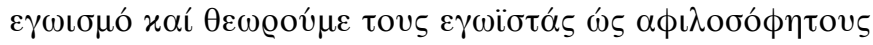

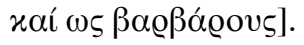

Correspondence to: Professor Demetrios A. Spandidos, Laboratory of Clinical Virology, School of Medicine, University of Crete, 71003 Heraklion, Greece

E-mail: spandidos@spandidos.gr

Key words: humility, Paediatric Virology, medical education, George N. Papanicolaou
What can be the connection between these philosophical texts by Dr Papanicolaou and his first scientific publication, a few years later, in Science (3), one of the most prestigious scientific journals to date? How did this junior doctor, who wrote philosophical texts on the value of humility, choose to perform his postgraduate studies in Germany and then a few years later across the Atlantic to New York, rather than to continue his family medical and political tradition on the island of Euboea? Was this choice by Dr Papanicolaou proof of his humility? How humble was he really, the son of the Mayor of Kymi, who while in New York was willing to work at a commercial centre, and to play violin in restaurants in order to earn his first income? What role did Dr Papanicolaou's philosophical opposition to egoism and egoists play in his outstanding research achievements and scientific evolution the following years? What was the key to his success, his beliefs in the achievement of high standards and values or his humility in order to achieve them? Was it indeed the strength of his knowledge or his humility to expand his knowledge? If he was himself an egoist, he would have considered that he knew everything and he would not have been thirsty for new knowledge. He would not have explored the best research centres to continue his medical education and research. He would have considered both his undergraduate studies in Athens and his planned medical and political career on his island as the best. Was his dedication to science a proof of humility, indeed? We had not managed to answer all these questions, until only recently, when in the second special issue on Paediatric Virology of the Experimental and Therapeutic Medicine, we interviewed 3 paediatric teachers (4-6), in the context of the '4th workshop on Paediatric Virology' held last year in Athens, Greece.

When Professor Alan Michael Weindling, Professor Emeritus of Perinatal Medicine at the University of Liverpool in the United Kingdom and former Head of the School of Paediatrics in Merseyside, was asked for his advice to junior paediatricians, his first advice was 'humility' (4). This was definitely not what we might have expected. In his editorial (7) based on this interview, humility was also included in the 7 fundamental principles for future paediatric education and more importantly, it was emphasized as the most significant 
among them. 'Humility helps you to realize that it is just not possible to know everything and that continuing learning is important', Professor Weindling explained (4). His explanation on the value of humility in medical training, continuing medical education and lifelong medical learning, reminded us of the quote by Socrates (470-399 B.C.) in his apology to the Athenians that 'All I know is that I know nothing' ["Ev oî $\delta \alpha$

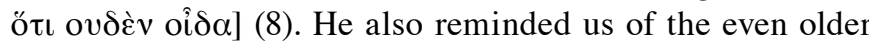
quote by the Athenian Solon (640-558 B.C.), one of the seven wise men of Ancient Greece, that 'I grow old learning some-

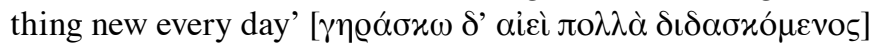
(9). How many times indeed have we realized how little we really know, the more we learn as medical scientists? Humility is indeed essential to medical education, both undergraduate and postgraduate; not simply to avoid the arrogance and hubris that often comes with knowledge, but also because our understanding of a number of diseases remains much more limited than we realize or want to believe and science in many cases cannot help. Even now, our knowledge can be further expanded; there are more treatments to be developed and medical conditions to be managed. Junior paediatricians should start their clinical practice with humility, strengthening their belief that they have a whole new world to learn and explore in Paediatrics. Even experienced medical professionals should always accept and acknowledge their mistakes, understanding that there are still fields in their specialties that they do not know.

In his interview (4), Professor Weindling also highlighted the role of humility in medical team working. 'I was very fortunate to find myself working with a great team of nurses and nurse practitioners, midwives and doctors. This team approach was one that I tried to teach' (4). Professor Alan Michael Weindling, one of the pioneers of modern neonatal care, worldwide, with an enormous contribution to the care of premature babies in the city of Liverpool, did not attribute his success to his knowledge, experience or excellence. He attributed his success to team work, a kind of scientific practice, which requires humility during the good and the bad times. Team work involves the rejection of egoism, self-centeredness, puffed-up pride and empty vanity or arrogance, along with a sober recognition of one's all-too-human limitations. 'We agreed, when I was appointed that we would try to offer similar care whichever of us was on duty and that if there was ever a situation where we could not agree, we would try to resolve it by a scientific approach' (4), he noted in the same interview referring to his collaboration with Professor Richard Cooke, his colleague at Liverpool Women's Hospital.

Dr Nikolaos Myriokefalitakis, one of the most talented teachers in Paediatrics in Greece, in our interview with him (5), also highlighted the value of humility in three different fields. The first one was the value of humility in the process of clinical diagnosis. 'If a physician, experienced or not, has performed a diagnosis before a thorough medical history and detailed physical examination of the patient, he or she will often fail' (5). How many times as medical students and later on as paediatric trainees have we indeed witnessed cases when the patient's diagnosis is performed without a detailed physical examination, or cases when the initial diagnosis is not changed despite increasing evidence to suggest it is wrong, even when clinical or laboratory findings propose a different diagnosis?
How many times has medical egoism not allowed us as medical professionals to re-evaluate our provisional diagnosis or admit our mistakes, thus accepting we do not really know everything? This has been termed diagnostic inertia (10), although an alternative term would be diagnostic narcissism or egoism. Throughout the process of clinical diagnosis, the doctor should be humble; this process is fundamental in the art and the science of Medicine and without any doubt this requires increased level of humility.

The second field according to Dr Myriokefalitakis is humility for the medical institution where a health professional works. When we described to him the 1st Paediatric Department of the 'Penteli' Children's Hospital as 'one of the most modern and exemplary paediatric departments in Greece' (5), he expressed a different opinion, albeit a realistic one: 'In my opinion, your term 'modern and exemplary paediatric department' is inordinate, not for the sake of moderation, but because this characterization is sadly far away from reality. A modern department cannot function 'in a vacuum'. There is a need for a thorough technological support, adequate medical and nursing staff, as well as the input of experts on basic specialties and paediatric sub-specialties; these conditions do not all exist. In the 1st Paediatric Department of the 'Penteli' Children's Hospital, we tried to deal with common and rare paediatric problems with realism and rationality, but also on the basis of current international guidelines. However, this logical and self-evident approach presents great difficulties in its implementation. It requires knowledge, experience and, above all, good 'medical philosophy' (5).

The third field for humility according to Dr Myriokefalitakis is humility for medical teachers. In one of his most touching answers in our interview, he mentioned that his younger colleagues, who have worked with him, appreciated most that he tried to transmit to them all the knowledge and experience he had gained throughout the years of his clinical practice in the hospital 'without sparing and selfishness' (5). Later on in his interview, he referred to the basic requirement in paediatric training summarised in the phrase 'train the trainers' (5). 'How many of us, who train our new colleagues, are eligible for this mission?' (5) he dared to ask. He emphasised the value of humility advising medical teachers to be open to new information and knowledge. Medical teachers should be thirsty to explore new knowledge and correct their wrong beliefs or practices; and it is of utmost importance and necessity for our future medical education that medical teachers are open-minded, promoting and updating their modes of teaching and inspiring their students with their innovation.

The third paediatric health professional, who was interviewed (6), was Dr Prakash Thiagarajan, Clinical Director of the Women's and Children's Health and lead Consultant Neonatologist at Noble's Hospital on the Isle of Man. We described him as 'one of the most talented Neonatologists in the UK with a great experience in newer modes of infant ventilation and the application of technology in Neonatal Medicine' (6) and he corrected us: 'Thank you for your kind words, but I believe I am one of many neonatologists, who do good work every day' (6). His answer was a real proof of humility for his everyday clinical practice, which is currently providing neonatal intensive care to infants born beyond 27 weeks of gestation on a Rhodes-shaped British island in 
the middle of the Irish Sea. How challenging is it for him to provide excellent care for neonates and support for their parents and families on the island? Dr Thiagarajan's answer was a real proof of humility for his state-of-the-art contribution to neonatal care, indeed. Moreover, although he was the one who had envisioned the new Neonatal Intensive Care Unit (NICU) at Noble's Hospital and was actively involved in its construction, in all his answers, he emphasised his collaboration with the local non-medical team. 'Please don't forget to mention the names of the lead neonatal nurse and the clinical general manager' he added in the final proof of corrections of our manuscript.

Scientific humility is the virtue that allows us to see ourselves and our medical science's abilities as they truly are. It is also the tool for avoiding a medical scientist's self-confidence that leads to hubris. But how can humility be combined with self-confidence? How can humility be practiced in Medicine, which according to Hippocrates (460-370 B.C.) is 'the most distinguished among all arts' (11)?

The answer is given by Aristotle (384-322 B.C.), the most important ancient Greek philosopher, who highlighted the value of 'moderation'; for Aristotle every virtue is a mean between vices. In his book called Nikomachean Ethics (12), he refers in detail to 'proper pride' [ $\left.\mu \varepsilon \gamma \alpha \lambda \mathrm{o} \psi v \chi_{i} \alpha\right]$, 'empty vanity'

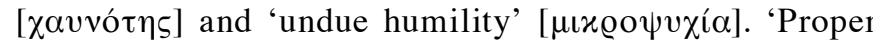
pride' is the virtue of appreciating oneself to the extent one deserves; it falls between 'empty vanity' and 'undue humility'. As the meanings of these terms have changed over the years, a better philosophical scaling for Aristotle's 'undue humility', 'proper pride' and 'empty vanity' would be 'self-devaluation', 'self-confidence' and 'self-arrogance'. Humility is the principle which enables your 'self-confidence' status not to grow into 'self-arrogance', while negative humility leads your 'self-confidence' status to change to 'self-devaluation'. But which of the two processes do we see more often?

Neonatal and paediatric health professionals are frequently required to manage ethically complex and challenging cases and regularly encounter situations where crucial life or death decisions need to be made (7). These can easily lead us to arrogance and hubris, exaggerating our scientific strength and abilities. How many times have we met arrogant medical scientists? How frequently does the self-esteem of medical scientists lead to self-overestimation and indeed hubris? Unfortunately, the answer is 'in many cases and even from the ancient times'. In Greek mythology, there is a very interesting legend regarding the end of Asclepius $(13,14)$, who according to Homer, was a real historical figure. Asclepius became very powerful in his ability to not only heal the sick but also raise the dead; however; this great achievement was against the will of the ancient Greek Gods. This is a really touching lesson of how vulnerable the medical profession is to hubris and how necessary humility is in clinical practice.

Without any doubt, humility is essential for medical education, clinical practice and creativity and future medical education should teach and cultivate it. This may require of us acts of passivity or self-limitation in response even to the slightest affronts that may border on the degrading or being shameful, acts to which the most natural reaction of any self-respecting person would be to fight back, and feel entirely justified in doing so. Everyone can realize how difficult the teaching and cultivation of humility is for young medical scientists and even more so for older medical scientists. Future medical education should teach medical scientists to exercise a healthy dose of humility in all stages of their medical career. It should teach them to admit throughout their career that their knowledge is but a drop of water in the Aegean Sea. Humility is a virtue to be taught in medical schools, postgraduate training and continuous lifelong learning.

\section{Acknowledgements}

This article is published in the third supplement issue of the Experimental and Therapeutic Medicine, which is dedicated to Paediatric Virology. This edition is performed in the context of the '5th workshop on Paediatric Virology' (Sparta, Greece, October 12, 2019) organized by the Paediatric Virology Study Group (PVSG) and supported by the Department of Clinical Virology of the University of Crete School of Medicine and the First Department of Paediatrics of the University of Athens School of Medicine. We would like to thank all the members of the PVSG for their valuable comments and corrections. We would also like to thank Dr Anastasia Stouraiti (London, United Kingdom) for her help in translating Dr George N. Papanicolaou's text, and Dr Melpomeni P. Kountouri (Geneva, Switzerland) and Mr. George D. Karapas (Adelaide, Australia) for reviewing our manuscript.

\section{References}

1. Mammas IN and Spandidos DA: George N. Papanicolaou (1883-1962): Fifty years after the death of a great doctor, scientist and humanitarian. J Buon 17: 180-184, 2012.

2. Papanicolaou GN: About egoism and egoists. O Noumas 319: 6-7, 1908 (In Greek).

3. Papanicolaou G: Sex determination and sex control in guinea-pigs. Science 41: 401-404, 1915.

4. Mammas IN and Spandidos DA: The future of medical education in neonatology, paediatrics and paediatric virology: An interview with Professor Alan Michael Weindling, Professor of Perinatal Medicine at the University of Liverpool. Exp Ther Med 16: 2805-2808, 2018.

5. Mammas IN and Spandidos DA: The philosophy of paediatric teaching: An interview with Dr Nikolaos Myriokefalitakis, former Clinical Director of the 'Penteli' Children's Hospital in Athens (Greece). Exp Ther Med 16: 2799-2802, 2018.

6. Mammas IN and Spandidos DA: Neonatology, paediatrics and paediatric virology on a British island: An interview with neonatologist Dr Prakash Thiagarajan (Isle of Man). Exp Ther Med 16: 2790-2794, 2018

7. Mammas IN, Spandidos DA and Weindling AM: The future of paediatric education. Exp Ther Med 16: 2803-2804, 2018.

8. Plato: The apology of Socrates. Kaktos Editions, Athens, 1992 (In Greek).

9. Plutarch: Vioi Paralliloi; Solon - Poplikolas. Kaktos Editions, Athens, 1992 (In Greek).

10. Isaacs D: From humiliation to humility. J Paediatr Child Health 54: 5-6, 2018.

11. Hippocrates: Law (Nomos). In: Hippocrates. Apanta 1. Kaktos Editions, Athens, 1993 (In Greek).

12. Aristotle: Apanta 9. Kaktos Editions, Athens, 1993 (In Greek)

13. Tsoulogiannis IN and Spandidos DA: Asclepius Sanctuaries in Laconia. Spandidos Publications, Athens, pp1-75, 2005.

14. Mammas IN and Spandidos DA: Medical humility and Greek mythology. J Paediatr Child Health 55: 999, 2019.

This work is licensed under a Creative Commons Attribution-NonCommercial-NoDerivatives 4.0 International (CC BY-NC-ND 4.0) License. 